\title{
Superoxide Anion, Uncoupling Proteins and Alzheimer's Disease
}

\author{
Zhaofei $\mathrm{Wu}^{1,2}$, Yan Zhao ${ }^{3}$ and Baolu Zhao ${ }^{1, *}$ \\ ${ }^{1}$ State Key Laboratory of Brain and Cognitive Sciences, Institute of Biophysics, Chinese Academy of Sciences, \\ 15 Datun Rd., Chaoyang District, Beijing 100101, the People's Republic of China \\ ${ }^{2}$ Graduate University of the Chinese Academy of Sciences, Beijing, the People's Republic of China \\ ${ }^{3}$ Department of Food Sciences and Technology, Harbin Institute of Technology at Weihai, 264209, China
}

Received 29 September, 2009; Accepted 27 November, 2009; Published online 20 March, 2010

\begin{abstract}
Summary Superoxide anion is the first generated reactive oxygen species (ROS) after oxygen enters living cells. It was once considered to be highly deleterious to cell functions and aging. Therefore, antioxidants were suggested to prevent aging and degenerative diseases. However, superoxide signaling has been shown in many physiological responses such as transcriptional regulation, protein activation, bioenergy output, cell proliferation and apoptosis. The uncoupling proteins (UCPs) are a family of mitochondrial anion-carrier proteins located in the inner mitochondrial membrane and are considered to reduce the generation of superoxide anion through the mitochondrial mild uncoupling. UCPs are important in prevention of mitochondrial excessive generation of ROS, transfer of mitochondrial substrates, mitochondrial calcium uniport and regulation of thermogenesis. Superoxide anion and uncoupling proteins are linked to Alzheimer's disease in mitochondria. Simultaneous disorders of superoxide and uncoupling proteins create the conditions for neuronal oxidative damages. On the one hand, sustained oxidative damage causes neuronal apoptosis and eventually, accumulated neuronal apoptosis, leading to exacerbations of Alzheimer's disease. On the other hand, our study has shown that UCP2 and UCP4 have important impact on mitochondrial calcium concentration of nerve cells, suggesting that their abnormal expression may involve in the pathogenesis of Alzheimer's disease.
\end{abstract}

Key Words: superoxide anion, uncoupling protein, Alzheimer's disease, oxidative stress, neurodegeneration

\section{Introduction}

Supoxide anion $\left(\mathrm{O}_{2}{ }^{--}\right)$is the first free radical of all reactive oxygen species (ROS) generated in vivo. Mitochondrial

*To whom correspondence should be addressed.

Tel: 861064888569 Fax: 861064871293

E-mail: zhaobl@sun5.ibp.ac.cn

\section{Biography}

Zhaofei $\mathrm{Wu}, \mathrm{PhD}$ candidate of Institute of Biophysics, Chinese Academy of Sciences, majors in biophysics. His main concern is the role of mitochondria in the pathogenesis of Alzheimer's disease.

Dr. Yan Zhao, received her Ph. D. degree in Nutritional Sciences respiratory chain is one of the main places where $\mathrm{O}_{2}{ }^{-}{ }^{-}$is produced [1]. A large number of studies have shown that $\mathrm{O}_{2}{ }^{--}$can initiate a variety of oxidative damage responses to phospholipids, proteins and nucleic acids by generating many kinds of oxygen free radicals, causing degenerative

from University of Kentucky and is currently an associate professor at Department of Food Sciences and Technology, Harbin Institute of Technology at Wehai. Her main research interest is nutrition and disease prevention.

Prof. Baolu Zhao, graduated from Graduate School of Chinese Academy of Sciences (1978-1981). He is awarded lifetime honorary membership of the Oxygen Club of California in recognition of his outstanding contribution to the field of free radical biology. His main research interest is involvements of free radicals and antioxidants in prevention of diseases 
diseases and aging [2]. Recently, it is found that the uncoupling proteins embedded in mitochondrial inner membrane are important molecules for the regulation of $\mathrm{O}_{2}{ }^{-}$ generation and protecting cells from oxidative damage [3]. Meanwhile, there's a growing body of evidence to suggest that $\mathrm{O}_{2}{ }^{--}$has important physiological functions in vivo, not only the culprit of cellular oxidative damage. It puts forward a theoretical challenge to the traditional concept of treating degenerative diseases and aging by using antioxidants to remove superoxide. This review will focus on the physiological functions of $\mathrm{O}_{2}{ }^{--}$and uncoupling proteins, and try to discuss their roles in the pathogenesis of Alzheimer's disease.

\section{Physiological Functions of $\mathrm{O}_{2}^{--}$}

Contrary to the once prevalent concept that $\mathrm{O}_{2}{ }^{--}$is highly deleterious to cell function and healthy aging, at present, an important role of superoxide signaling has been discovered in a variety of physiological responses such as transcriptional activation, bioenergy output, cell proliferation, and apoptosis [4].

\section{Transcriptional activation}

New developments of superoxide anion participation in enzymatic phosphorylation/dephosphorylation reactions are of particular interest. These processes are mainly related to protein kinase cascade. Baas and Berk have found that $\mathrm{O}_{2}{ }^{--}$ activated mitogen-activated protein kinases (MAPK) in vascular smooth muscle cells by a way different from $\mathrm{H}_{2} \mathrm{O}_{2}$ in 1995 [5]. Huang et al. suggested that the peroxisome proliferator activated receptor- $\gamma$ (PPAR- $\gamma$ ) agonists stimulation of extracellular signal-related protein kinase (EPK) phosphorylation in murine myoblasts was mediated by $\mathrm{O}_{2}{ }^{--}[6]$. It was found that mitochondrial superoxide modulated nuclear cAMP-responsive element-binding protein (CREB) phosphorylation in hippocampal neurons [7]. The activity of the important nuclear transcription factor $\mathrm{NF} \kappa \mathrm{B}$ is regulated by $\mathrm{O}_{2}{ }^{-}$formation. $\mathrm{NF} \kappa \mathrm{B}$ is maintained in the cytosol in an inactive form bound to the inhibitor $\mathrm{I} \kappa \mathrm{B} \alpha$. Following plasma membrane superoxide and $\mathrm{H}_{2} \mathrm{O}_{2}$ formation, induced by various cell effectors (e.g. cytokines, hormones), and regulated by Ras 1 (G protein), a transduction protein phosphokinase acts to phosphorylate $\mathrm{I} \kappa \mathrm{B} \alpha$. This phosphorylation results in dissociation of the complex, I $\kappa \mathrm{B} \alpha-\mathrm{P}$ ubiquitination and its destruction by the proteasome, and release of NFKB to translocate to the nucleus and function as a major transcription regulator [8]. Interestingly, recent evidence appears to directly implicate $\mathrm{Na}^{+} / \mathrm{H}^{+}$transporter 1 (NHE1), which is strongly suggested as a key molecule in redoxmediated cell fate decisions, as a downstream target of intracellular ROS such that an increase in intracellular $\mathrm{O}_{2}{ }^{-}$ stimulates NHE1 promoter activity and gene expression [9].

\section{Cell differentiation and proliferation}

There is a growing literature on normally produced extracellular effectors determining the intracellular redox state of cells and consequently in some instances the course of cellular self-propagation or differentiation. As shown by Smith et al, an intracellular redox environment induced to favour a more oxidized state by thyroid hormone or bone morphogenic protein 4 leads to a differentiation of the precursor cells into oligodendrocytes or astrocytes. On the other hand, an intracellular redox environment induced to favour a more reducing state by basic fibroblast growth factor or platelet-derived growth factor promotes selfpropagation of the precursor cells [10].

A substantial body of data support the involvement of low levels of $\mathrm{O}_{2}{ }^{--}$in proliferative signaling. Increased, nontoxic $\mathrm{O}_{2}{ }^{--}$levels achieved by downregulation of SOD with antisense oligonucleotides inhibited apoptosis, whereas overexpression of SOD or inhibition of $\mathrm{NAD}(\mathrm{P}) \mathrm{H}$ oxidase led to a decrease in $\mathrm{O}_{2}{ }^{--}$and increased susceptibility of cells to undergo apoptosis [11]. Mild elevation in intracellular $\mathrm{O}_{2}{ }^{--}$stimulates growth responses in a variety of cell types via activation of early growth-related genes such as c-fos and c-jun, alterations in the activities of protein kinases, oxidative inactivation of phosphatases, and activation of transcription factors $[12,13]$. It seems that $\mathrm{O}_{2}{ }^{--}$can serve as a growth signal in different cells via a rac/ras-NAD $(\mathrm{P}) \mathrm{H}$ oxidase-MAPK signaling pathway [13]. Oberley et al. showed that overexpression of the oncogenic form of the small $\mathrm{G}$ protein $\mathrm{v}-\mathrm{Ha}$-ras increased $\mathrm{O}_{2}{ }^{\cdot-}$ generation and the growth of the human keratinocyte cell line HaCaT. In contrast, overexpression of virally transduced SOD blocked the growth-stimulatory effect of v-Ha-ras overexpression, suggesting that intracellular $\mathrm{O}_{2}{ }^{--}$was responsible for this effect. In addition to the keratinocyte cell line, rat kidney epithelial cells could also be stimulated to grow and form colonies in soft agar in an $\mathrm{O}_{2}{ }^{--}$-dependent manner by v-Haras overexpression [14].

A few studies also suggested the involvement of $\mathrm{O}_{2}{ }^{--}$in differentiation signaling. Wang et al. have reported that $\mathrm{O}_{2}{ }^{--}$ can promote osteogenic differentiation of mesenchymal stem cells using animal and cell models [15]. Lately, reduced expression of the NADPH oxidase NOX4 was suggested as a hallmark of adipocyte differentiation. Data suggest an appealing scenario where in preadipocytes an initial insulininduced "burst" in superoxide production may trigger signaling events leading to the initialization of the adipocyte differentiation process and eventually to the downregulation of NOX4 and the upregulation of insulin receptor expression [16].

\section{Immunoprotection}

$\mathrm{T}$ cell activation during an immune response is strongly augmented in the presence of $\mathrm{O}_{2}{ }^{--}$or at relatively low 
concentrations of $\mathrm{H}_{2} \mathrm{O}_{2}$ via ROS dependent increase in IL-2 promoter activity and transcription and surface expression of the IL-2 receptor [17]. Macrophage plasma membrane NADPH oxidase is a potent source of very high concentrations of $\mathrm{O}_{2}{ }^{--}$and hydrogen peroxide $(\mathrm{mM})$ employed for the killing of sequestrated pathogen [18]. Moreover, recent findings suggest that ROS generated from the NADPH oxidase complex contribute to monocyte/macrophage survival [19].

Regulation of energy metabolism- $\mathrm{Ca}^{2+}$ regulating messenger

$\mathrm{Wu}$ and de Champlain have shown that superoxide enhanced the hydrolysis of phosphatidylinositol (PIP) to inositol 1,4,5-tris-phosphate (IP3) in rat aortic smooth muscle cells [20]. The regulation of calmodulin (CM) function by $\mathrm{O}_{2}{ }^{-}$/hydrogen peroxide oxidation of specific methionine residues is now well-documented [21]. The oxidation of methionine residues at positions 144 and 145 of $\mathrm{CM}$ is involved in down regulation of plasma membrane (PM) $\mathrm{Ca}^{2+}$ ATPase activity [22]. It has also been reported from the same laboratory that methionine sulfoxide reductase can act reductively to restore the ability of oxidized CM to regulate $\mathrm{PM}-\mathrm{Ca}^{2+}$ ATPase [23]. These results indicate that $\mathrm{O}_{2}{ }^{-} /$hydrogen peroxide functions as part of the controlled regulation of the $\mathrm{CM}-\mathrm{PM}-\mathrm{Ca}^{2+}$ ATPase complex.

The regulated prooxidant formation of the $\mathrm{O}_{2}{ }^{-}-\mathrm{H}_{2} \mathrm{O}_{2}$ second messenger system is essential for the normal physiological function of the metabolome. The normally functioning metabolome is the expression of a dynamic equilibrium comprised of thousands of anabolic and catabolic reactions, which are finely tuned by signaling systems. There is still much to be learnt about the up/down regulation of these messenger systems. The concept that $\mathrm{O}_{2}{ }^{-}-/ \mathrm{H}_{2} \mathrm{O}_{2}$ causes random macromolecular damage should be discussed according to the specific cellular environment. Thus, the administration of antioxidants to quench the inferred toxicity of these compounds as a therapy for age associated diseases should be subjected to serious evaluation and needs to be supported by results from animal models and clinical trials [24].

\section{Inhibition of apoptosis}

Recent findings have demonstrated that a mild increase in intracellular superoxide inhibited apoptosis in tumor cells, irrespective of the trigger [25]. The discovery of the death inhibitory activity of intracellular $\mathrm{O}_{2}{ }^{--}$has challenged the dogmatic view that ROS are deleterious to cell growth and survival. It appears that a permissive intracellular environment for apoptotic signaling is a function of a tight balance between intracellular $\mathrm{O}_{2}{ }^{-}$and $\mathrm{H}_{2} \mathrm{O}_{2}$, and that a decrease in intracellular $\mathrm{O}_{2}{ }^{--}$or a reciprocal increase in $\mathrm{H}_{2} \mathrm{O}_{2}$ facilitates apoptotic execution [26]. Earlier data implicated Racdependent increase in intracellular $\mathrm{O}_{2}{ }^{--}$in the mitogenic signaling that is induced upon the activation of Ras [27].
As shown by Pervaiz et al., expression of a constitutively active form of Rac1 in human melanoma cells (M14) resulted in a mild increase in intracellular $\mathrm{O}_{2}{ }^{--}$with a concomitant decrease in the sensitivity of tumor cells to apoptosis [28].

\section{Regulation of protein activity and protein turnover}

One of the established effects of $\mathrm{O}_{2}{ }^{--}$in signaling is the activation of the ras/rac-Raf1-MAPK pathway [29]. Angiotensin II (ANG II) induces $\mathrm{O}_{2}{ }^{--}$generation in endothelial cells via the ubiquitous $\mathrm{NAD}(\mathrm{P}) \mathrm{H}$ oxidase. This $\mathrm{O}_{2}{ }^{--}$then activates the Raf-1-MAPK pathway, leading to altered gene expression. ANG II has also been shown to stimulate $\mathrm{O}_{2}{ }^{--}$ production in the central nervous system to increase vasopressin secretion and sympathetic outflow. This was confirmed in vivo as adenoviral vector-mediated expression of SOD (AdSOD) in mice blocked both ANG II-induced $\mathrm{O}_{2}{ }^{--}$ generation and changes in blood pressure, heart rate, and drinking behavior.

Huang et al. recently demonstrated that ERK activation induced by PPAR- $\gamma$ agonists was blocked by a SOD mimetic and induced by an $\mathrm{O}_{2}{ }^{--}$-generating system, representing another example that $\mathrm{O}_{2}{ }^{--}$affecting protein activity [6]. Moreover, as previously described, $\mathrm{O}_{2}{ }^{--}$can activate nuclear transcription factor NFKB [8].

Obviously, protein activation is an important function of $\mathrm{O}_{2}{ }^{--}$. Conventionally, protein modifications by ROS and reactive nitrogen species (RNS) are considered as random and highly undesirable, leading to protein malfunction. In turn, these modified proteins must be removed by proteasome-catalyzed degradation. However, contrary to this concept, current viewpoints suggest that $\mathrm{NO}$ /peroxynitrite and $\mathrm{O}_{2}{ }^{-}-/ \mathrm{H}_{2} \mathrm{O}_{2}$ do not simply randomly damage proteins, instead, they play important roles in the regulated proteolysis and homeostasis of proteins. One example of protein degradation promoted by $\mathrm{O}_{2}{ }^{--}$as mentioned above is the regulation of calmodulin activity $[21,22]$.

In addition, $\mathrm{O}_{2}{ }^{--}$continually formed in small amounts during the oxidation of hemoglobin $(\mathrm{Hb})$ to met $\mathrm{Hb}$ in the order of a steady state amount of $1-3 \%$. The met $\mathrm{Hb}$ formed is continually reduced back to $\mathrm{Hb}$ by erythrocyte met $\mathrm{Hb}$ reductase to maintain oxygen homeostasis [18]. It suggests that the production of superoxide anion related to the body's oxygen supply.

\section{Physiological Functions of Uncoupling Proteins}

The UCPs are a family of mitochondrial anion-carrier proteins that are located on the inner mitochondrial membrane. The UCP superfamily comprises integral membrane proteins that share structural and functional similarities. A common feature is a tripartite structure, with three repeats of $\sim 100$ amino acids, each containing two hydrophobic 
stretches that correspond to transmembrane alpha helices. The two transmembrane helices in each repeat are linked by a long hydrophilic loop, which is orientated towards the matrix side of the membrane, and the amino and carboxyl termini of UCP extend into the intermembrane space. Interestingly, anion carriers and channel proteins most frequently rely on the formation of alpha-helical stretches with 12 membrane-spanning regions, and the functional unit of UCPs is a homodimer formed by two identical subunits that contain 12 transmembrane helices. Therefore, although UCP4 and BMCP1 are divergent in amino acid sequence compared with UCP1, they share a common protein structure with UCP1-3, which underlies functional anion-carrier proteins.

Mitochondrial uncoupling mediated by UCP1 is classically associated with non-shivering thermogenesis by brown fat. Recent evidence indicates that UCP family proteins are also present in selected neurons. Notably, UCP4 and BMCP1 (also known as UCP5) have been shown to be highly expressed in the central nervous system. Unlike UCP1, these proteins (UCP2, UCP4 and BMCP1/UCP5) are not constitutive uncouplers and are not crucial for the non-shivering thermogenesis. However, they can be activated by free radicals and free fatty acids, and their activity has a profound influence on neuronal functions [30]. Except for UCP1, the precise physiological functions of UCPs have not yet been established. Following are several viewpoints about the physiological functions of UCPs.

\section{Regulation of ROS production}

UCPs are thought to be responsible for an inducible, mild uncoupling of mitochondria that may be able to prevent excessive mitochondrial ROS production [3, 31]. A lot of articles support this view, but it is hard to tell whether regulation of ROS production is the main function of UCPs or just the side effect of the main function.

\section{Transportation of mitochondrial substrates}

UCP3 expressed in glycolytic muscle fibres may be a passive pyruvate transporter ensuring equilibrium between glycolysis and oxidative phosphorylation. Induction of UCP2 expression by glutamine strengthens the hypothesis that newly discovered UCPs could act to determine the choice of mitochondrial substrate [31].

\section{Calcium regulation}

Mitochondria have evolved as important cytosolic calcium buffers. Since calcium cannot be metabolized like other second-messenger molecules, intracellular calcium must be tightly regulated to maintain homeostasis. UCP2 and UCP3 were reported to be fundamentally involved in mitochondrial $\mathrm{Ca}^{2+}$ uniport, the process that represents the main pathway sequestrating $\mathrm{Ca}^{2+}$ into the mitochondrial matrix
[32]. UCP4, a neuronal UCP, was also reported to regulate cellular $\mathrm{Ca}^{2+}$ homeostasis [33]. As mitochondria are enriched in presynaptic terminals, and the calcium milieu of axon terminals is important in vesicle traffic, fusion, release and recycling, regulation of presynaptic calcium concentrations by UCPs is expected to affect neurotransmission directly [30]. Our study shows that UCP2 and UCP4 have an important impact on mitochondrial calcium concentration of nerve cells, suggesting that their abnormal expression may be involved in the pathogenesis of AD [34].

\section{Thermogenesis in microenvironments}

CNS areas rich in UCPs (such as the hypothalamus) have a higher local temperature than areas relatively devoid of UCPs (for example, the striatum and thalamus, which have a $2.7 \%$ reduction compared with the hypothalamus), despite steady core body temperature. Recent evidence indicates that temperature gradients created by neuronal UCPs enhance the migration of chemical signals from a cell source to high-affinity receptors on cells for the signal, especially in brain regions where there are mismatches in innervation and receptor localization [35].

In short, by regulating mitochondrial biogenesis, calcium flux, free radical production and local temperature, neuronal UCPs can directly influence neurotransmission, synaptic plasticity and neurodegenerative processes. Insights into the regulation and function of these proteins offer unsuspected avenues for a better understanding of synaptic transmission and neurodegeneration [30].

\section{The Roles of $\mathrm{O}_{2}^{--}$and Uncoupling Proteins in the Pathogenesis of Alzheimer's Disease}

Alzheimer's disease affects almost $2 \%$ of the population in industrialized countries and the risk is significantly increased in individuals of more than 70 years of age. It is characterized by neurofibrillary tangle formation in neuronal perikarya and extracellular deposits of amyloid- $\beta$ protein [36]. Unfortunately, up to date we still have no effective cure for this disease. The studies over the past one hundred years haven't given a complete answer for its etiology and pathogenesis. Therefore, according to new research data to explore the etiology and pathogenesis of $\mathrm{AD}$ from different perspectives is necessary.

\section{The roles of $\mathrm{O}_{2}^{--}$in the pathogenesis of $A D$}

There is extensive literature supporting a role of oxidative damage in the pathogenesis of AD and oxidative damage probably contribute causally to AD-related pathology [2]. Oxidative damage occurs early in the $\mathrm{AD}$ brain, before the onset of significant plaque pathology. Oxidative damage also precedes $A \beta$ deposition in transgenic APP mice, with up-regulation of genes relating to mitochondrial metabolism 
and apoptosis occurring even earlier and co-localizing with the neurons undergoing oxidative damage. In a transgenic APP-mutant mouse, hemizygous deficiency of the mitochondrial antioxidant enzyme MnSOD markedly increased brain A $\beta$ levels and plaque deposition [37]. $\mathrm{O}_{2}{ }^{--}$is the precursor of many other ROS, thus its production may initiate the oxidative damage seen in AD brain.

Several cell signaling pathways linking oxidative stress and $\mathrm{AD}$ pathology have been uncovered recently. Specifically, oxidative stress may activate signaling pathways that alter APP or tau processing. For example, oxidative stress increases the expression of $\beta$-secretase through activation of c-Jun amino-terminal kinase and p38 MAPK, and increases aberrant tau phosphorylation by activation of glycogen synthase kinase 3 [38]. Oxidant-induced inactivation of critical molecules may also be important. In a proteomic study, the prolyl isomerase PIN1 was found to be particularly sensitive to oxidative damage. PIN1 catalyses protein conformational changes that affect both APP and tau processing. Knockout of Pin1 increases amyloidogenic APP processing and intracellular A $\beta$ levels in mice [39]. PIN1knockout mice also exhibit tau hyperphosphorylation, motor and behavioural deficits, and neuronal degeneration [40]. Therefore, oxidative stress may lead to AD-related pathological changes by inactivating PIN1.

AD was associated with significantly increased expression of the p53 pro-apoptosis gene, all 3 isoforms of nitric oxide synthase (NOS 1-3), and NOX 1 and NOX 3, beginning early in the course of disease. Activation of cytoprotective mechanisms in $\mathrm{AD}$ brains is limited since the expression of uncoupling protein 2, 4, and 5, and PPAR alpha and delta genes is significantly reduced, whereas PPAR-gamma expression is selectively increased. The results demonstrate that $\mathrm{AD}$ is associated with early and striking increases in the molecular indices of oxidative stress. The simultaneous reductions in cyto-protective mechanisms (UCP and PPAR), could allow oxidative injury to go unchecked and persist or increase over time. Adopting strategies to reduce the effects of NOS and NOX activities, and improve the actions of UCPs and PPARs may help in the treatment of AD [41].

Notably, mitochondrion is the bridge to link together $\mathrm{O}_{2}{ }^{--}$, UCPs and AD. Converging evidences suggest that most of the proteins implicated in $\mathrm{AD}$ pathogenesis have direct physical involvement with mitochondria or mitochondrial proteins. APP has been found to have a dual endoplasmic reticulum/mitochondrial-targeting sequence, and in cells and transgenic mice overexpressing APP it clogged the mitochondrial protein importation machinery, causing mitochondrial dysfunction and impaired energy metabolism [42]. $\mathrm{A} \beta$ binds to a mitochondrial-matrix protein termed $A \beta$ binding alcohol dehydrogenase (ABAD). Blocking the interaction of $\mathrm{A} \beta$ and $\mathrm{ABAD}$ with a 'decoy peptide' suppressed $\mathrm{A} \beta$-induced apoptosis and free-radical generation in neurons. Conversely, overexpression of ABAD in transgenic APP-mutant mice exaggerated neuronal oxidative stress and impaired memory [43]. Two other groups have also reported that $\mathrm{A} \beta$ interacts with mitochondria, inhibiting cytochrome oxidase activity and increasing freeradical generation [44]. A $\beta$ also inhibits $\alpha$-ketoglutarate dehydrogenase activity in isolated mitochondria, and deficiency of $\alpha$-ketoglutarate dehydrogenase and cytochrome oxidase activities has previously been observed in the brain and other tissues in $\mathrm{AD}$ [45]. $\mathrm{A} \beta$ also interacts with the serine protease HTRA2 (also known as OMI) [46]. Presenilin and all the other components of the $\gamma$-secretase complex have also been localized to mitochondria, where they form an active $\gamma$-secretase complex [47].

It should be noted that most cells possess enzymatic systems that are capable of producing $\mathrm{O}_{2}{ }^{-}$, whereas to date no cellular system is known to exclusively generate $\mathrm{H}_{2} \mathrm{O}_{2}$. In most cases, the first reaction of $\mathrm{O}_{2}$ is the one-electron reduction $\mathrm{O}_{2}{ }^{\cdot-}$. Although many biological effects have been ascribed to $\mathrm{H}_{2} \mathrm{O}_{2}$ and have been extensively discussed elsewhere, the insight starts to emerge that $\mathrm{O}_{2}{ }^{--}$may be a more important mediator of cellular effects [12].

\section{The roles of UCPs in the pathogenesis of $A D$}

As mentioned above, once the expression levels of UCP 2, 4, 5 were significantly decreased, the ability of neurons from $\mathrm{AD}$ brain to be protected from oxidative stress damage was impaired. The impairment of the cell self-protection mechanism (UCPs and PPARs) makes it possible for the oxidative damage to persist unrestrictedly, even exacerbate over time.

Intriguingly, $\mathrm{O}_{2}{ }^{--}$themselves can induce the expression of UCPs, including UCP2 and UCP4 [34], and activate proton transport through UCP1-3 [48]. Moreover, products of oxidative stress, such as 4-hydroxy-2-nonenal, may also regulate mitochondrial uncoupling [49]. Therefore, ROSinduced uncoupling might act as a simple feedback mechanism to limit the extent of oxidative cell damage, which could lead to protection against neurodegenerative diseases and ageing.

Tangles and plaques are found predominantly in areas of $\mathrm{AD}$ brain that regulate learning, memory and emotional behaviours, including the hippocampus, cortex, basal forebrain and brain stem. Interestingly, these brain regions also express neuronal UCPs. Although there are no studies directly linking neuronal uncoupling activity to Alzheimer's disease, neuronal UCPs might regulate many of the pathogenic mechanisms that lead to neuronal degeneration, such as increased oxidative damage, perturbed cellular calcium homeostasis, impaired energy metabolism and synaptic dysfunction [36]. Indeed, UCP4 modulates neuronal energy metabolism by increasing glucose uptake and shifting the 
mode of ATP production from mitochondrial respiration to glycolysis, thereby maintaining cellular ATP levels [50], and abnormalities in glucose regulation and insulin resistance are risk factors for Alzheimer's disease [51]. Furthermore, dietary restriction, which protects neurons from dysfunction and death in models of Alzheimer's disease [36], also enhances UCP4 expression in the cortex and hippocampus [52]. Our study shows that UCP2 and UCP4 modulate mitochondrial calcium concentration of nerve cells, and can be regulated by $\mathrm{O}_{2}{ }^{--}$, suggesting that this dysfunction of mitochondrial calcium may be involved in the pathogenesis of $\mathrm{AD}[34]$.

\section{Concluding Remarks}

In summary, $\mathrm{O}_{2}{ }^{--}$is an oxygen free radical with important physiological functions in vivo; UCPs are proteins with important physiological functions in vivo. $\mathrm{O}_{2}{ }^{--}$is like a sharp double-edged sword, on the one hand, activating gene transcription, promoting cell growth and proliferation and inhibiting apoptosis, on the other hand, leading to oxidative stress, causing apoptosis. Neuronal UCPs can resist oxidative stress or maintain the calcium regulation capability of mitochondria to play a role in preventing the neurodegeneration of Alzheimer's disease. Simultaneous disorders of $\mathrm{O}_{2}{ }^{-}$and uncoupling proteins create the conditions for the neuronal oxidative damage. Sustained oxidative damage can further cause neuronal apoptosis and eventually, extended neuronal death, leading to exacerbations of Alzheimer's disease. Block oxidative damage and balance of free radicals generation may inhibit neuronal apoptosis and eventually prevent and cure Alzheimer's disease.

\section{Acknowledgments}

This work was supported by National Natural Science Foundation of China (30170239) and 973 grant (2006CB500700).

\section{Abbreviations}

UCPs, uncoupling proteins; AD, Alzheimer's disease; ROS, reactive oxygen species; MAPK, mitogen-activated protein kinase; PPAR- $\gamma$, peroxisome proliferator activated receptor- $\gamma$; EPK, extracellular signal-related protein kinase; CREB, cAMP-responsive element-binding protein; NFKB, nuclear factor- $\mathrm{kB}$; NHE1, $\mathrm{Na}^{+} / \mathrm{H}^{+}$transporter 1 ; NOX, NADPH oxidase; PIP, phosphatidylinositol; IP3, inositol 1,4,5-tris-phosphate; CM, Calmodulin; PM, plasma membrane; ANG II, angiotensin II; AdSOD, adenoviral vectormediated expression of SOD; RNS, reactive nitrogen species; $\mathrm{Hb}$, hemoglobin; PIN1, peptidyl-prolyl cis/trans isomerase; APP, amyloid precursor protein; NOS, nitric oxide synthase; $\mathrm{ABAD}, \mathrm{A} \beta$-binding alcohol dehydrogenase.

\section{References}

[1] Grivennikova, V.G. and Vinogradov, A.D.: Generation of superoxide by the mitochondrial Complex I. Biochim. Biophys. Acta, 1757, 553-561, 2006.

[2] Lin, M.T. and Beal, M.F.: Mitochondrial dysfunction and oxidative stress in neurodegenerative diseases. Nature, $\mathbf{4 4 3}$, 787-795, 2006.

[3] Echtay, K.S.: Mitochondrial uncoupling proteins-what is their physiological role?. Free Radic. Biol. Med., 43, 13511371, 2007.

[4] Afanas'ev, I.B.: On mechanism of superoxide signaling under physiological and pathophysiological conditions. Med. Hypotheses, 64, 127-129, 2005.

[5] Baas, A.S. and Berk, B.C.: Differential activation of mitogenactivated protein kinases by $\mathrm{H} 2 \mathrm{O} 2$ and $\mathrm{O} 2-$ in vascular smooth muscle cells. Circ. Res., 77, 29-36, 1995.

[6] Huang, W.C., Chio, C.C., Chi, K.H., Wu, H.M., and Lin, W.W.: Superoxide anion-dependent Raf/MEK/ERK activation by peroxisome proliferator activated receptor gamma agonists 15-deoxy-delta(12,14)-prostaglandin $\mathrm{J}(2)$, ciglitazone, and GW1929. Exp. Cell Res., 277, 192-200, 2002.

[7] Hongpaisan, J., Winters, C.A., and Andrews, S.B.: Calciumdependent mitochondrial superoxide modulates nuclear CREB phosphorylation in hippocampal neurons. Mol. Cell. Neurosci., 24, 1103-1115, 2003.

[8] Voet, D. and Voet, J.D.: Biochemistry, New Jersey, USA, John Wiley and Sons, 2004.

[9] Akram, S., Teong, H.F., Fliegel, L., Pervaiz, S., and Clement, M.V.: Reactive oxygen species-mediated regulation of the $\mathrm{Na}+\mathrm{H}+$ exchanger 1 gene expression connects intracellular redox status with cells' sensitivity to death triggers. Cell Death Differ, 13, 628-641, 2006.

[10] Smith, J., Ladi, E., Mayer-Proschel, M., and Noble, M.: Redox state is a central modulator of the balance between self-renewal and differentiation in a dividing glial precursor cell. Proc. Natl. Acad. Sci. U.S.A., 97, 10032-10037, 2000.

[11] Pimentel, D.R., Amin, J.K., Xiao, L., Miller, T., Viereck, J., Oliver-Krasinski, J., Baliga, R., Wang, J., Siwik, D.A., Singh, K., Pagano, P., Colucci, W.S., and Sawyer, D.B.: Reactive oxygen species mediate amplitude-dependent hypertrophic and apoptotic responses to mechanical stretch in cardiac myocytes. Circ. Res., 89, 453-460, 2001.

[12] Sauer, H., Wartenberg, M., and Hescheler, J.: Reactive oxygen species as intracellular messengers during cell growth and differentiation. Cell. Physiol. Biochem., 11, 173-186, 2001.

[13] Buetler, T.M., Krauskopf, A., and Ruegg, U.T.: Role of superoxide as a signaling molecule. News Physiol. Sci., 19, 120-123, 2004.

[14] Yang, J.Q., Buettner, G.R., Domann, F.E., Li, Q., Engelhardt, J.F., Weydert, C.D., and Oberley, L.W.: v-Ha-ras mitogenic signaling through superoxide and derived reactive oxygen species. Mol. Carcinog., 33, 206-218, 2002. 
[15] Wang, F.S., Wang, C.J., Sheen-Chen, S.M., Kuo, Y.R., Chen, R.F., and Yang, K.D.: Superoxide mediates shock wave induction of ERK-dependent osteogenic transcription factor (CBFA1) and mesenchymal cell differentiation toward osteoprogenitors. J. Biol. Chem., 277, 10931-10937, 2002.

[16] Mouche, S., Mkaddem, S.B., Wang, W., Katic, M., Tseng, Y.H., Carnesecchi, S., Steger, K., Foti, M., Meier, C.A., Muzzin, P., Kahn, C.R., Ogier-Denis, E., and Szanto, I.: Reduced expression of the NADPH oxidase NOX4 is a hallmark of adipocyte differentiation. Biochim. Biophys. Acta, 1773, 1015-1027, 2007.

[17] Droge, W.: Free radicals in the physiological control of cell function. Physiol. Rev., 82, 47-95, 2002.

[18] Linnane, A.W., Kios, M., and Vitetta, L.: Healthy aging: regulation of the metabolome by cellular redox modulation and prooxidant signaling systems: the essential roles of superoxide anion and hydrogen peroxide. Biogerontology, $\mathbf{8}$, 445-467, 2007.

[19] Wang, Y., Zeigler, M.M., Lam, G.K., Hunter, M.G., Eubank, T.D., Khramtsov, V.V., Tridandapani, S., Sen, C.K., and Marsh, C.B.: The role of the NADPH oxidase complex, p38 MAPK, and Akt in regulating human monocyte/macrophage survival. Am. J. Respir. Cell Mol. Biol., 36, 68-77, 2007.

[20] Wu, L. and de Champlain, J.: Effects of superoxide on signaling pathways in smooth muscle cells from rats. Hypertension, 34, 1247-1253, 1999.

[21] Yin, D., Sun, H., Weaver, R.F., and Squier, T.C.: Nonessential role for methionines in the productive association between calmodulin and the plasma membrane Ca-ATPase. Biochemistry, 38, 13654-13660, 1999.

[22] Yin, D., Kuczera, K., and Squier, T.C.: The sensitivity of carboxyl-terminal methionines in calmodulin isoforms to oxidation by $\mathrm{H}(2) \mathrm{O}(2)$ modulates the ability to activate the plasma membrane Ca-ATPase. Chem. Res. Toxicol., 13, 103$110,2000$.

[23] Sun, H., Gao, J., Ferrington, D.A., Biesiada, H., Williams, T.D., and Squier, T.C.: Repair of oxidized calmodulin by methionine sulfoxide reductase restores ability to activate the plasma membrane Ca-ATPase. Biochemistry, 38, 105-112, 1999.

[24] Linnane, A.W., Kios, M., and Vitetta, L.: Coenzyme Q(10)its role as a prooxidant in the formation of superoxide anion/ hydrogen peroxide and the regulation of the metabolome. Mitochondrion, 7 Suppl, S51-S61, 2007.

[25] Clement, M.V., Hirpara, J.L., and Pervaiz, S.: Decrease in intracellular superoxide sensitizes Bcl-2-overexpressing tumor cells to receptor and drug-induced apoptosis independent of the mitochondria. Cell Death Differ., 10, 1273-1285, 2003.

[26] Pervaiz, S. and Clement, M.V.: A permissive apoptotic environment: function of a decrease in intracellular superoxide anion and cytosolic acidification. Biochem. Biophys. Res., 290, 1145-1150, 2002.

[27] Irani, K. and Goldschmidt-Clermont, P.J.: Ras, superoxide and signal transduction. Biochem. Pharmacol., 55, 13391346, 1998.

[28] Pervaiz, S., Cao, J., Chao, O.S., Chin, Y.Y., and Clement,
M.V.: Activation of the RacGTPase inhibits apoptosis in human tumor cells. Oncogene, 20, 6263-6268, 2001.

[29] Brandes, R.P.: Role of NADPH oxidases in the control of vascular gene expression. Antioxid. Redox Signal., 5, 803811, 2003.

[30] Andrews, Z.B., Diano, S., and Horvath, T.L.: Mitochondrial uncoupling proteins in the CNS: in support of function and survival. Nat. Rev., 6, 829-840, 2005.

[31] Hurtaud, C., Gelly, C., Chen, Z., Levi-Meyrueis, C., and Bouillaud, F.: Glutamine stimulates translation of uncoupling protein 2mRNA. Cell Mol. Life Sci., 64, 1853-1860, 2007.

[32] Trenker, M., Malli, R., Fertschai, I., Levak-Frank, S., and Graier, W.F.: Uncoupling proteins 2 and 3 are fundamental for mitochondrial Ca2+ uniport. Nat. Cell Biol., 9, 445-452, 2007.

[33] Chan, S.L., Liu, D., Kyriazis, G.A., Bagsiyao, P., Ouyang, X., and Mattson, M.P.: Mitochondrial uncoupling protein-4 regulates calcium homeostasis and sensitivity to store depletioninduced apoptosis in neural cells. J. Biol. Chem., 281, 37391-37403, 2006.

[34] Wu, Z., Zhang, J., and Zhao, B.: Superoxide anion regulates the mitochondrial free $\mathrm{Ca} 2+$ through uncoupling proteins. Antioxid. Redox Signal., 11, 1805-1818, 2009.

[35] Horvath, T.L., Warden, C.H., Hajos, M., Lombardi, A., Goglia, F., and Diano, S.: Brain uncoupling protein 2: uncoupled neuronal mitochondria predict thermal synapses in homeostatic centers. J. Neurosci., 19, 10417-10427, 1999.

[36] Mattson, M.P.: Pathways towards and away from Alzheimer's disease. Nature, 430, 631-639, 2004.

[37] Li, F., Calingasan, N.Y., Yu, F., Mauck, W.M., Toidze, M., Almeida, C.G., Takahashi, R.H., Carlson, G.A., Flint Beal, M., Lin, M.T., and Gouras, G.K.: Increased plaque burden in brains of APP mutant MnSOD heterozygous knockout mice. J. Neurochem., 89, 1308-1312, 2004.

[38] Lovell, M.A., Xiong, S., Xie, C., Davies, P., and Markesbery, W.R.: Induction of hyperphosphorylated tau in primary rat cortical neuron cultures mediated by oxidative stress and glycogen synthase kinase-3. J. Alzheimers Dis., 6, 659-671, discussion 673-681, 2004.

[39] Pastorino, L., Sun, A., Lu, P.J., Zhou, X.Z., Balastik, M., Finn, G., Wulf, G., Lim, J., Li, S.H., Li, X., Xia, W., Nicholson, L.K., and Lu, K.P.: The prolyl isomerase Pin1 regulates amyloid precursor protein processing and amyloidbeta production. Nature, 440, 528-534, 2006.

[40] Liou, Y.C., Sun, A., Ryo, A., Zhou, X.Z., Yu, Z.X., Huang, H.K., Uchida, T., Bronson, R., Bing, G., Li, X., Hunter, T., and $\mathrm{Lu}, \mathrm{K} . \mathrm{P}$. .: Role of the prolyl isomerase Pin1 in protecting against age-dependent neurodegeneration. Nature, 424, 556$561,2003$.

[41] de la Monte, S.M. and Wands, J.R.: Molecular indices of oxidative stress and mitochondrial dysfunction occur early and often progress with severity of Alzheimer's disease. $J$. Alzheimers Dis., 9, 167-181, 2006.

[42] Anandatheerthavarada, H.K., Biswas, G., Robin, M.A., and Avadhani, N.G.: Mitochondrial targeting and a novel transmembrane arrest of Alzheimer's amyloid precursor protein impairs mitochondrial function in neuronal cells. J. Cell 
Biol., 161, 41-54, 2003.

[43] Lustbader, J.W., Cirilli, M., Lin, C., Xu, H.W., Takuma, K., Wang, N., Caspersen, C., Chen, X., Pollak, S., Chaney, M., Trinchese, F., Liu, S., Gunn-Moore, F., Lue, L.F., Walker, D.G., Kuppusamy, P., Zewier, Z.L., Arancio, O., Stern, D., Yan, S.S., and $\mathrm{Wu}, \mathrm{H} .: \mathrm{ABAD}$ directly links Abeta to mitochondrial toxicity in Alzheimer's disease. Science, 304, 448-452, 2004.

[44] Crouch, P.J., Blake, R., Duce, J.A., Ciccotosto, G.D., Li, Q.X., Barnham, K.J., Curtain, C.C., Cherny, R.A., Cappai, R., Dyrks, T., Masters, C.L., and Trounce, I.A.: Copperdependent inhibition of human cytochrome c oxidase by a dimeric conformer of amyloid-beta1-42. J. Neurosci., 25, 672-679, 2005.

[45] Casley, C.S., Canevari, L., Land, J.M., Clark, J.B., and Sharpe, M.A.: Beta-amyloid inhibits integrated mitochondrial respiration and key enzyme activities. J. Neurochem., 80, 91100, 2002.

[46] Park, H.J., Seong, Y.M., Choi, J.Y., Kang, S., and Rhim, H.: Alzheimer's disease-associated amyloid beta interacts with the human serine protease HtrA2/Omi. Neurosci. Lett., 357, 63-67, 2004.

[47] Hansson, C.A., Frykman, S., Farmery, M.R., Tjernberg, L.O., Nilsberth, C., Pursglove, S.E., Ito, A., Winblad, B., Cowburn, R.F., Thyberg, J., and Ankarcrona, M.: Nicastrin, presenilin, APH-1, and PEN-2 form active gamma-secretase complexes in mitochondria. J. Biol. Chem., 279, 5165451660, 2004.

[48] Echtay, K.S., Roussel, D., St-Pierre, J., Jekabsons, M.B., Cadenas, S., Stuart, J.A., Harper, J.A., Roebuck, S.J., Morrison, A., Pickering, S., Clapham, J.C., and Brand, M.D.: Superoxide activates mitochondrial uncoupling proteins. Nature, 415, 96-99, 2002.

[49] Echtay, K.S., Esteves, T.C., Pakay, J.L., Jekabsons, M.B., Lambert, A.J., Portero-Otin, M., Pamplona, R., Vidal-Puig, A.J., Wang, S., Roebuck, S.J., and Brand, M.D.: A signalling role for 4-hydroxy-2-nonenal in regulation of mitochondrial uncoupling. EMBO J., 22, 4103-4110, 2003.

[50] Liu, D., Chan, S.L., de Souza-Pinto, N.C., Slevin, J.R., Wersto, R.P., Zhan, M., Mustafa, K., de Cabo, R., and Mattson, M.P.: Mitochondrial UCP4 mediates an adaptive shift in energy metabolism and increases the resistance of neurons to metabolic and oxidative stress. Neuromolecular Med., 8, 389-414, 2006.

[51] Watson, G.S. and Craft, S.: The role of insulin resistance in the pathogenesis of Alzheimer's disease: implications for treatment. CNS Drugs, 17, 27-45, 2003.

[52] Mattson, M.P. and Liu, D.: Mitochondrial potassium channels and uncoupling proteins in synaptic plasticity and neuronal cell death. Biochem. Biophys. Res. Commun., 304, 539-549, 2003. 